\title{
Geophysical Study: Estimation of Deposit Depth Using Gravimetric Data and Euler Method (Jalalabad Iron Mine, Kerman Province of IRAN)
}

\author{
Adel Shirazy¹, Aref Shirazi', Hamed Nazerian'2, Keyvan Khayer ${ }^{3 *}$, Ardeshir Hezarkhani4 \\ ${ }^{1}$ Department of Mining Engineering, Amirkabir University of Technology (Tehran Polytechnic), Tehran, Iran \\ ${ }^{2}$ Department of Civil Engineering and Architecture, University of Catania, Catania, Italy \\ ${ }^{3}$ Faculty of Mining, Petroleum \& Geophysics Engineering, Shahrood University of Technology, Shahrood, Iran \\ ${ }^{4}$ Amirkabir University of Technology, Tehran, Iran \\ Email: ^K.khayer@shahroodut.ac.ir
}

How to cite this paper: Shirazy, A., Shirazi, A., Nazerian, H., Khayer, K. and Hezarkhani, A. (2021) Geophysical Study: Estimation of Deposit Depth Using Gravimetric Data and Euler Method (Jalalabad Iron Mine, Kerman Province of IRAN). Open Journal of Geology, 11, 340-355. https://doi.org/10.4236/ojg.2021.118018

Received: July 5, 2021

Accepted: August 8, 2021

Published: August 11, 2021

Copyright $\odot 2021$ by author(s) and Scientific Research Publishing Inc. This work is licensed under the Creative Commons Attribution-NonCommercial International License (CC BY-NC 4.0). http://creativecommons.org/licenses/by-nc/4.0/ (c) (i) (3) Open Access

\begin{abstract}
Mineral exploration is done by different methods. Geophysical and geochemical studies are two powerful tools in this field. In integrated studies, the results of each study are used to determine the location of the drilling boreholes. The purpose of this study is to use field geophysics to calculate the depth of mineral reserve. The study area is located $38 \mathrm{~km}$ from Zarand city called Jalalabad iron mine. In this study, gravimetric data were measured and mineral depth was calculated using the Euler method. 1314 readings have been performed in this area. The rocks of the region include volcanic and sedimentary. The source of the mineralization in the area is hydrothermal processes. After gravity measuring in the region, the data were corrected, then various methods such as anomalous map remaining in levels one and two, upward expansion, first and second-degree vertical derivatives, analytical method, and analytical signal were drawn, and finally, the depth of the deposit was estimated by Euler method. As a result, the depth of the mineral deposit was calculated to be between 20 and 30 meters on average.
\end{abstract}

\section{Keywords}

Geophysical Study, Depth Estimation, Gravimetric Data, Euler Method, Jalalabad Iron Mine

\section{Introduction}

Today, mineral exploration involves a variety of methods and techniques [1] [2] 
[3]. These methods include geochemical exploration, geophysical exploration, satellite image analysis, and remote sensing [4]-[10]. The results of these studies are evaluated using statistical and analytical methods [11] [12] [13]. Geostatistical methods, intelligent analysis (such as machine learning) is a practical and important tool in optimizing and increasing the accuracy of results [14] [15] [16]. Part of the study of mineral exploration includes studies of mineral processing. Because in order to go to the next stages of exploration, the feasibility of mineral processing must be done to be economical [17] [18] [19] [20]. During the life cycle of a mine, which begins with exploration and ends with reconstruction, various studies are performed. One of them is the feasibility of using mineral areas and geological attractions as geotourism targets [21]. In this research, using geophysical analysis methods, the depth of mineral reserves has been determined. The basis of the gravimetric method is to determine the gravitational acceleration changes between different parts of the Earth, due to changes in gravity acceleration between different parts of the Earth's surface. According to the changes in gravity acceleration, it is possible to determine how the density of rocks is distributed underground. If a geological deposit or building is located underground in a particular order and has a significant density difference with its surrounding environment, it can create a specific gravitational acceleration distribution on the Earth's surface. By determining the changes in gravity at the Earth's surface with the help of gravimetric methods, it is possible to understand the existence or non-existence of a geological deposit or structure and how it is located. This method tries to eliminate all other factors that cause changes in the acceleration of gravity in the area so that changes in gravity acceleration can be considered only due to changes in the density of underground buildings. The residual anomaly is positive on deposits with a density more significant than the density of the surrounding rock and negative with a density less than the density of the rocks within them. By interpreting the residual anomaly data, it is possible to obtain valuable information about the quantitative and qualitative characteristics of mineral masses such as location, extent, depth, and slope of the mineral and an estimate of approximate storage [22].

Gravimetric and magnetometric methods are among the geophysical methods that play an influential role in exploring and exploring iron ore deposits. The magnetometric method, in which changes in the Earth's magnetic field are measured and studied, is more straightforward and smoother than the gravimetric method in terms of field and office work. However, the information obtained from this method is more qualitative, and due to the more complex nature of the Earth's magnetic field than the gravitational field, the quantitative interpretation of its data is not straightforward [23]. In contrast, the gravimetric method is a method of field extraction that is slower and more difficult, and therefore more expensive, but less information about the mineral can be obtained from gravimetric data. In this study, by combining gravimetric and magnetometric information of the study area, the exact location of iron mineralization and the depth 
of mineralization were determined using the power spectrum analysis method.

\section{Geology of the Region}

The study area is located $38 \mathrm{~km}$ from Zarand city in Kerman province. This area, known as the Jalalabad iron mine, has several iron anomalies. The rocks of the area are of the volcanic and sedimentary type of the Rizo series. The mineralization of the region is of hydrothermal type and is the result of an intercontinental rift and uplift of sodium-alkaline magma and melt melting. From geological evidence, the presence of shaped lens mineralization is predicted to be northwest-southeast. The geological survey of the area can be seen in Figure 1 .

Geologically, the study area is one of the sedimentary units of Central Iran, which is located between the Kuhbanan fault in the east and the Davaran fault in the west. In this area, Precambrian deposits called Sri Murad are spread in the west of the region and Paleozoic, Mesozoic, and Tertiary in the east of the region. The Rizo series is located on the Murad series with a regular conglomerate and an angular deformation. The series is a sequence of sedimentary rocks, 30 degrees north-carbonate, destructive and volcanic with an overall slope of 50

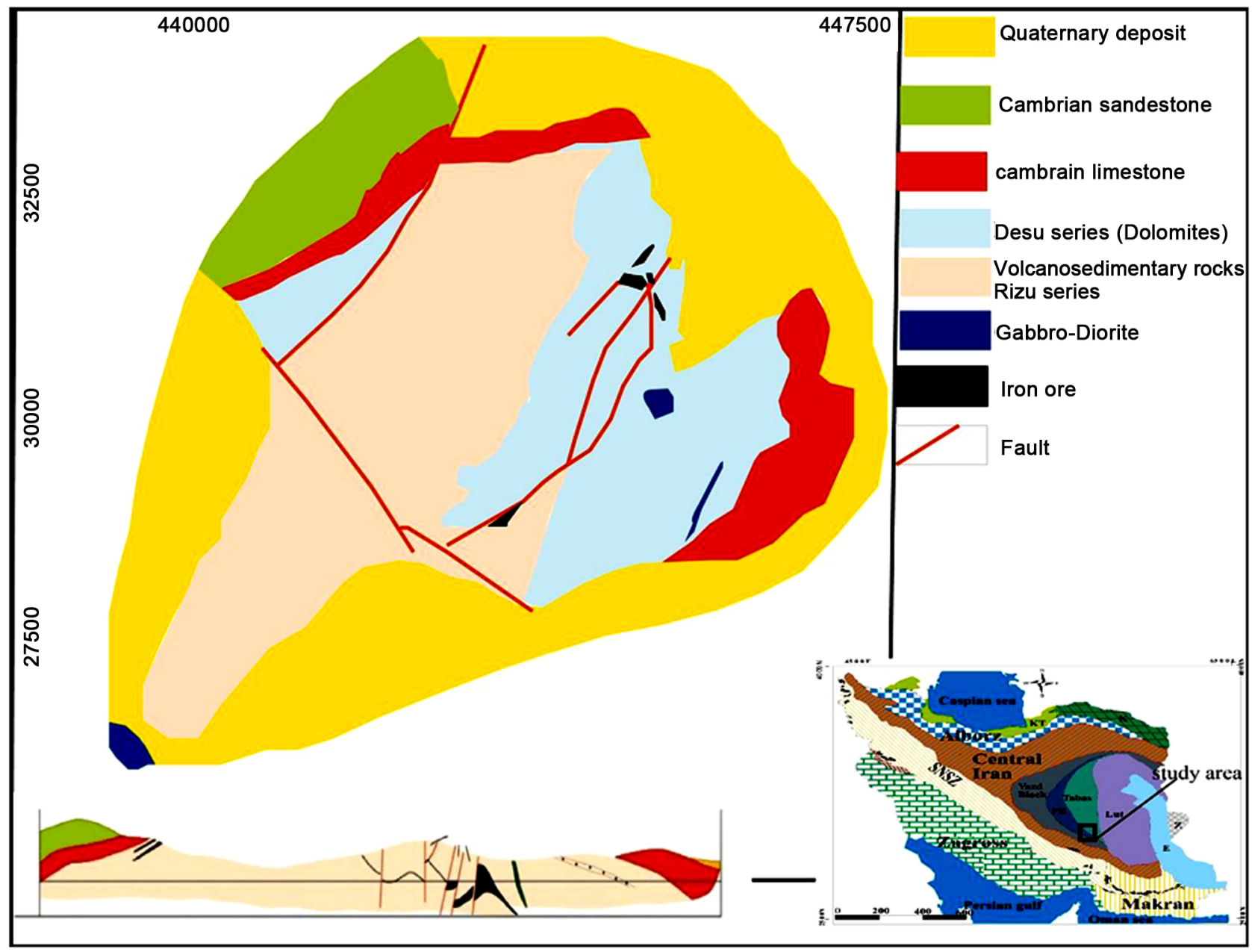

Figure 1. Geological map of Jalal Abad mining district [24]. 
degrees east-southwest and located along the anticline. There are greenish-gray, pink sandstones, and sandstone shales with a heterogeneous composition of sediments and glacial rocks and conglomerate fragments of carbonate rocks in the fine-grained paste in the lower part.

Acidic and basaltic volcanic rocks with split alteration, which indicate bi-medal magmatism and rift position of the area, are observed along with the mineral's hematite and magnetite. In the upper part, there are carbonate rocks, chert dolomite, dolomite, along with jasper, which is an indicator of the marine environment. The carbonate-dolomite cap, formed in the interglacial-post-glacial age, after the migration and retreat of glaciers and the advance of the sea, extensively covers the upper part of the series.

Jalalabad deposit has a reserve of about 200 million tons of iron ore with an average grade of 55 to 60 percent. The host rock of iron mineralization in the Jalalabad deposit is volcanic-sedimentary rocks of the Rizo series. Mineralization has taken place in sandstone, siltstone, volcanoclastic rocks, dolomite, and dolomitic limestones.

Small igneous masses of micro gabbro type and a number of dykes and floods with a combination of micro diorite and diabase are exposed in the area. The primary ore of the deposit is Magnetite and is located in deep parts, and hematite is mainly secondary to the oxidation of magnetite and is abundant in shallow and shallow parts and fracture sites. Pyrite and chalcopyrite are sulfide ores found in the Jalalabad deposit.

The major non-metallic minerals are quartz, which, together with dolomite, talc, chlorite, sericite, ferroactinolite, and calcite from the waste minerals. There is an alteration in the Jalalabad deposit, and it has created halos around the deposit, and its most important types include sodium, chlorite, sericite, and siliceous alteration.

\section{Study Method}

Before preparing potential maps in the study area, the collected data should be processed, and the necessary corrections should be made about them. Anomalous maps prepared from potential method impressions are generated from various objects at different depths with different densities. The values taken include the effects of the collection of these masses from bottom to top. That is, what is harvested relates to all anomalies. In the Boge anomaly map, the effects of soft rock topography and gentle linear changes will show, which are called regional effects or regional gravity. Computational methods or drawing methods can eliminate regional effects. For this purpose, by reducing these values, which include serious effects, Bogge values, surface effects are obtained [25] [26].

Since in field methods Figure 2, the potential distribution of objects causing the anomaly is not the same, and the effects of a mass are not helpful. Therefore, the shapes and depths of the anomalous masses are different, and the changes in the Boge anomaly map will include all the masses in the harvest area [27]. Therefore, 


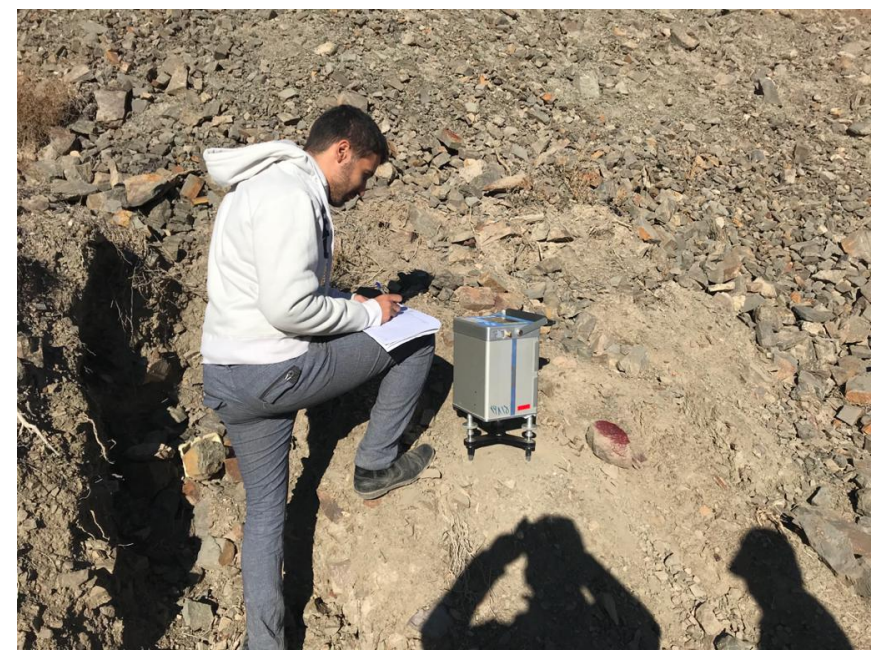

Figure 2. Gravimetric measurement of the area by the authors.

if there is a uniform distribution potential in the methods or there is no density change between the objects, there will be no discussion of the contents of the anomalies and their separation, and the changes will be linear. Infield maps, the potential of deep masses covers a wide range in anomalous maps instead of the surface effects of small areas. Therefore, the residual anomaly values will be expressed according to Equation (1):

$$
g_{\text {res }}=g_{b}-g_{\text {reg }}
$$

Residual effects $=$ Boge values - Area effects

Interpretation of potential field data is divided into two parts: qualitative interpretations and quantitative interpretations. In the following, first the qualitative interpretations of the data and then the quantitative interpretations will be discussed [28] [29].

\subsection{Qualitative Interpretation}

To separate the area anomalies from the Boge values, the trend level analysis method was used with the 1st and 2nd-degree levels, and the 2nd level, which was better in line with the data and showed the anomaly more clearly, was used for the next steps.

\subsubsection{Boge Anomaly Map}

In the first step, using corrections made on the data, the Boge anomaly map of the region was drawn according to Figure 3 in Geosoft software. This map shows the effect of masses causing anomalies at different depths, which have a bottom-up effect and have caused changes in gravity acceleration in the area.

The process level analysis method was used to obtain the remaining anomalies. This method is such that a page with different degrees is passed on the captured information. Therefore, the basis of this method is based on the surface that has the most suitability, in other words, the best agreement with the observed values. In the trend level method, this level is selected for geophysical 


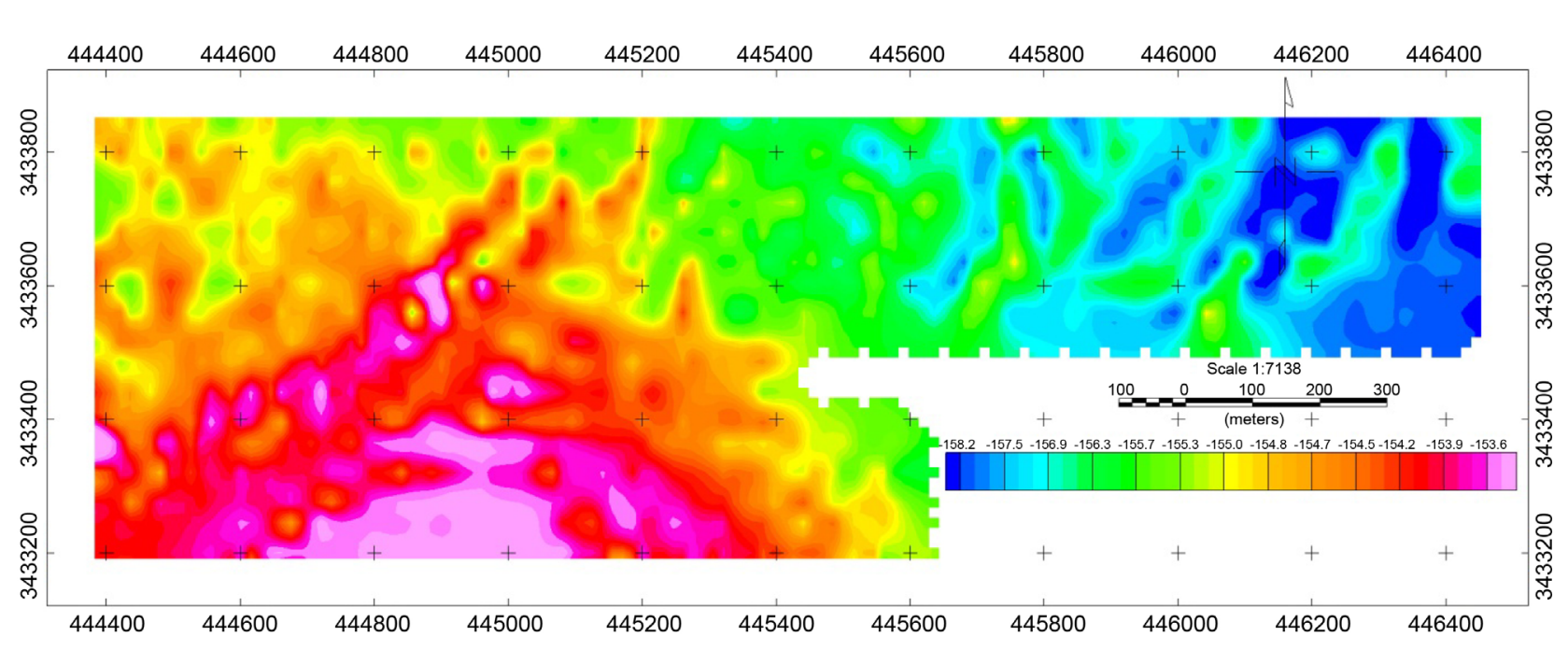

Figure 3. Map of Boge anomalous changes.

information as the effects of regions, and after passing this level on the practical information, the remaining geophysical information will be obtained [27]. Therefore, if $G_{i}$ is the practical information and $T_{i}$ is the surface information, $R_{i}$ is the remaining information will be obtained from Equation (2):

$$
R_{i}=G_{i}-T_{i}
$$

The local effects are:

$$
T(x)=A_{0}+A_{1} x+A_{2} x_{2}+\cdots+A_{n} x_{n}
$$

In two-dimensional mode:

$$
T(x, y)=A_{00}+A_{10} x+A_{01} y+A_{11} x^{2}+A_{21} x^{2} y+\cdots+A_{p q} x_{p} y_{q}
$$

Furthermore, this is if the sum of the remainder should be close to zero [30]. That is mean:

$$
\sum R_{i} \approx 0
$$

In which case, the remaining information squares. That is, the square of the difference between the observed information and the surface trend information should have the most negligible value (least-squares method):

$$
\sum_{i=1}^{n} R_{i}^{2}=\sum\left(G_{i}-T_{i}\right)^{2}=\text { the lessest value }
$$

The higher the degree of the surface trend, the greater the possibility of accessing the most appropriate surface or consistent with the observed values, so the ideal trend for a separation process is an anomaly. Figure 4 and Figure 5 show the residual map obtained from the 1st- and 2nd-degree levels. Because Level 2 is a better indication of the anomaly, this map was used as a benchmark for later interpretations.

\subsubsection{Upward Expansion Map}

One of the methods of separating the field anomaly is the potential for upward expansion. By using this method, surface effects are eliminated, and profound 


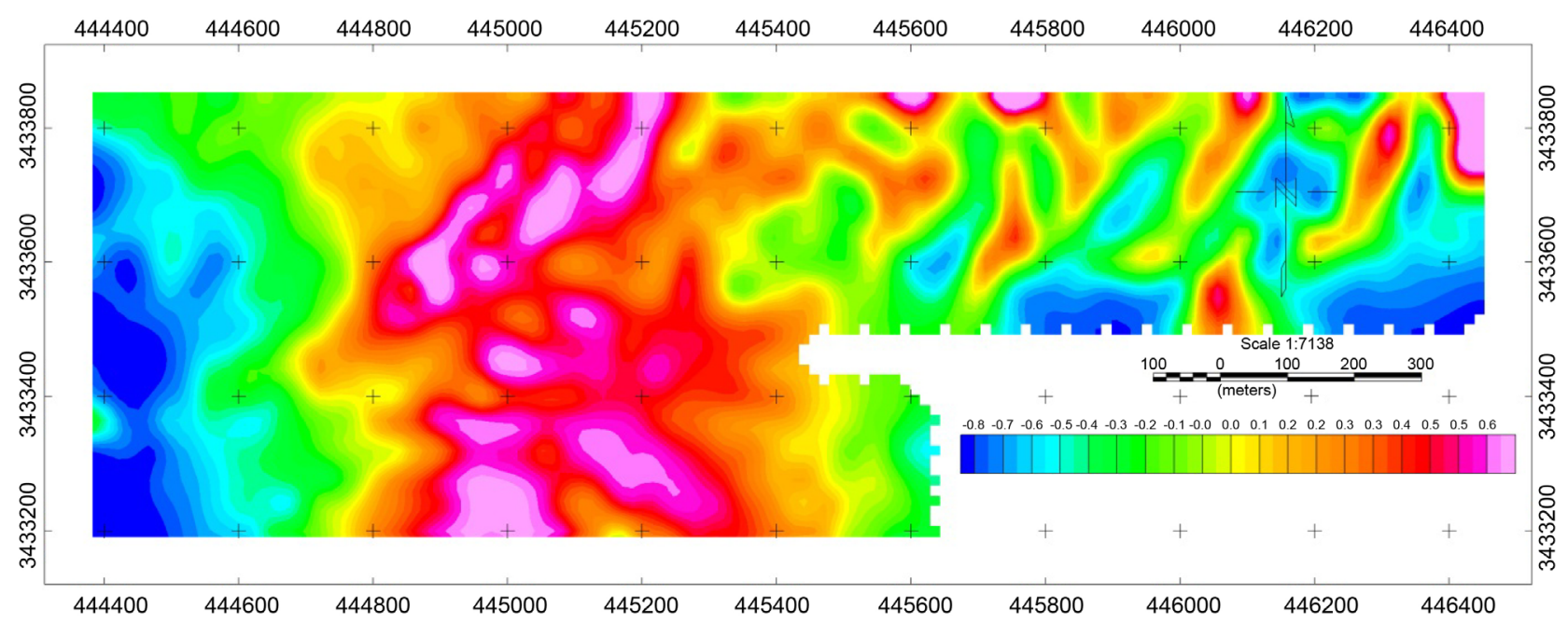

Figure 4. Residual anomaly map obtained from 1st-degree level.

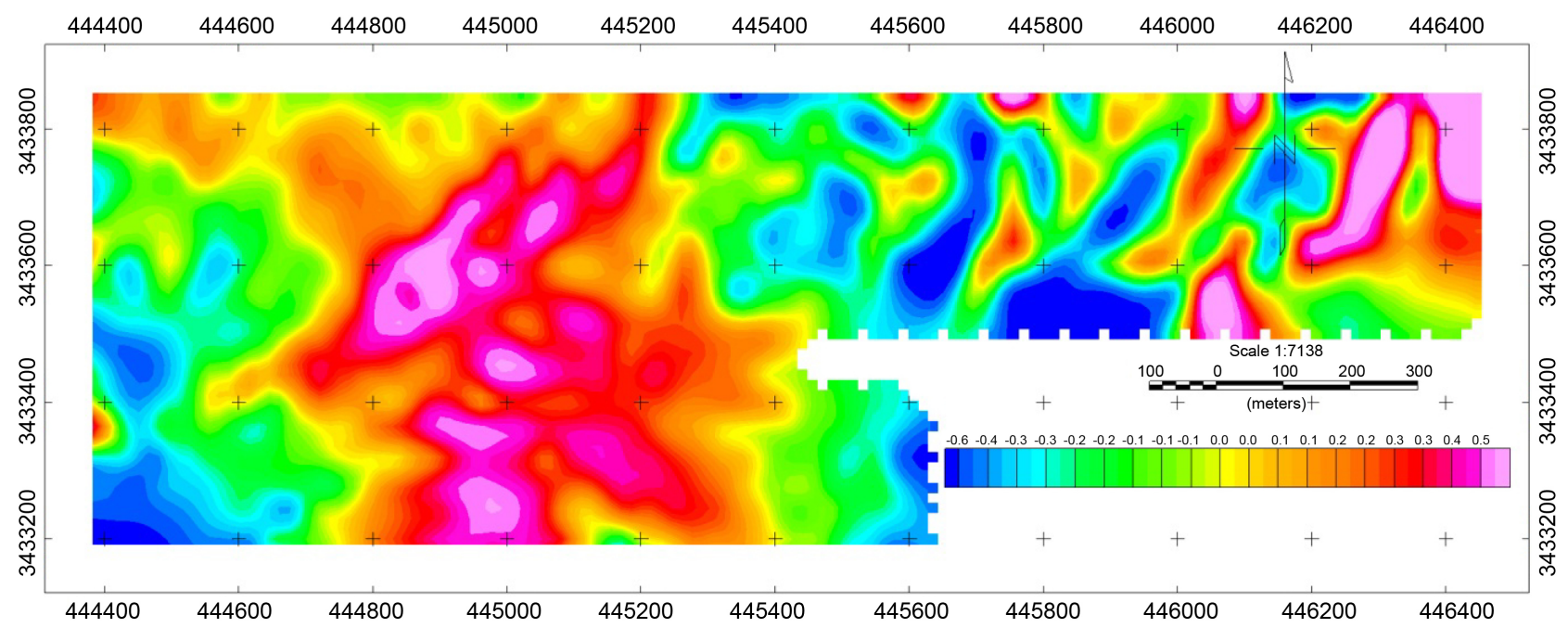

Figure 5. Residual anomaly map obtained from 2nd-degree level.

effects are identified. In this method, potential field data is mathematically represented from a base surface on alignment surfaces above the main base surface. Upward expansion is smoothing.

In upward expansion maps, the farther away we are from the earth's surface, the smaller and smaller the anomalies become, leaving only regional anomalies. This method eliminates anomalies with shorter wavelengths, weakens the anomalies' amplitude, and reduces noise. So, this method works like a low-pass method. In this method, the Boge anomaly is imaged by the following relation from the data collection surface on the alignment levels above the harvesting surface [31] [32].

$$
g_{B h}=\frac{1}{N}\left[\left(g_{B 1} \times \frac{h_{1} A}{2 \Pi R_{1}^{3}}\right)+\left(g_{B 2} \times \frac{h_{2} A}{2 \Pi R_{2}^{3}}\right)+\cdots+\left(g_{B N} \times \frac{h_{N} A}{2 \Pi R_{N}^{3}}\right)\right]
$$

where $\left(g_{B 1}, g_{B 2}, \cdots\right.$, and $\left.g_{B N}\right)$ the Boge anomaly is networked at $(N)$ points on area 
( $A$ ) of the map. $(R)$ The distance of points on the grid to the desired point is at height $h$. Continuous maps are one of the most critical indicators in obtaining a fast finger depth estimate as efficient methods in potential field perceptions [33] [34]. Upward expansion maps were drawn from 20 to $140 \mathrm{~m}$. Moreover, since the anomaly did not change much from 100 to 120 , the depth of the anomaly is about 100 meters. Figures 6-11 show the anomalous changes during the transverse process from 20 to 140 .

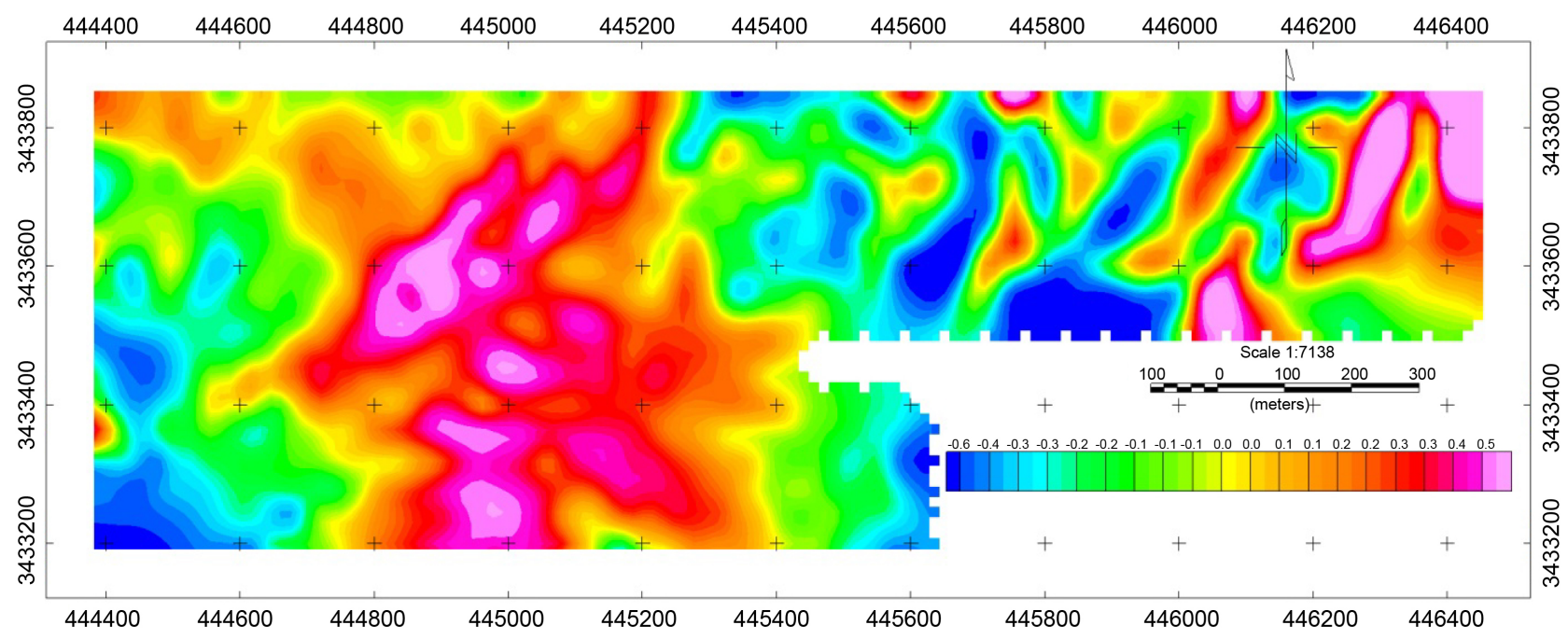

Figure 6. Map extends upwards with a height of 20 meters.

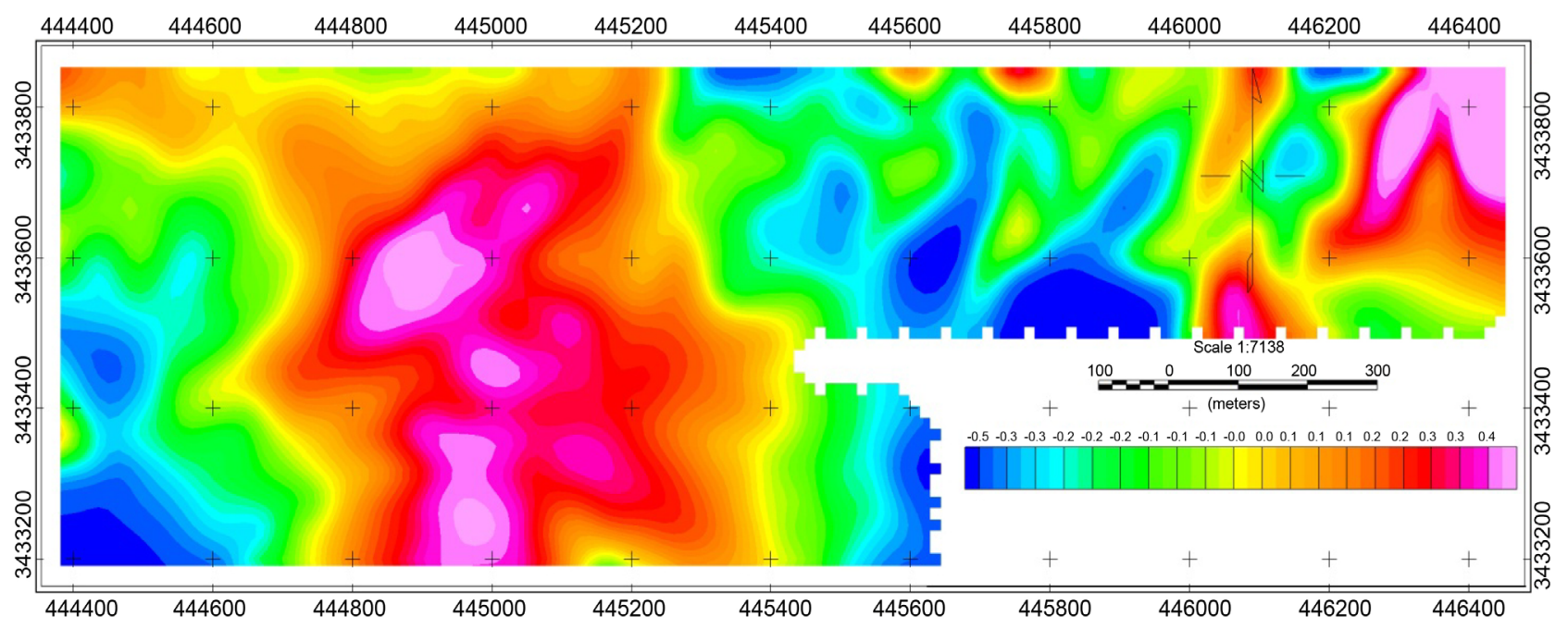

Figure 7. Map extends upwards with a height of 40 meters.

\subsubsection{First and Second-Order Vertical Derivative Map}

One standard method for distinguishing surface anomalies from the strong effects of the first and second derivative methods is:

$$
\mathrm{d} g / \mathrm{d} z \text { and } \mathrm{d}^{2} g / \mathrm{d} z^{2}
$$

In derivative maps, the regional and deep effects are very weakened or eliminated due to their linearity, in which case the surface effects will be shown more 


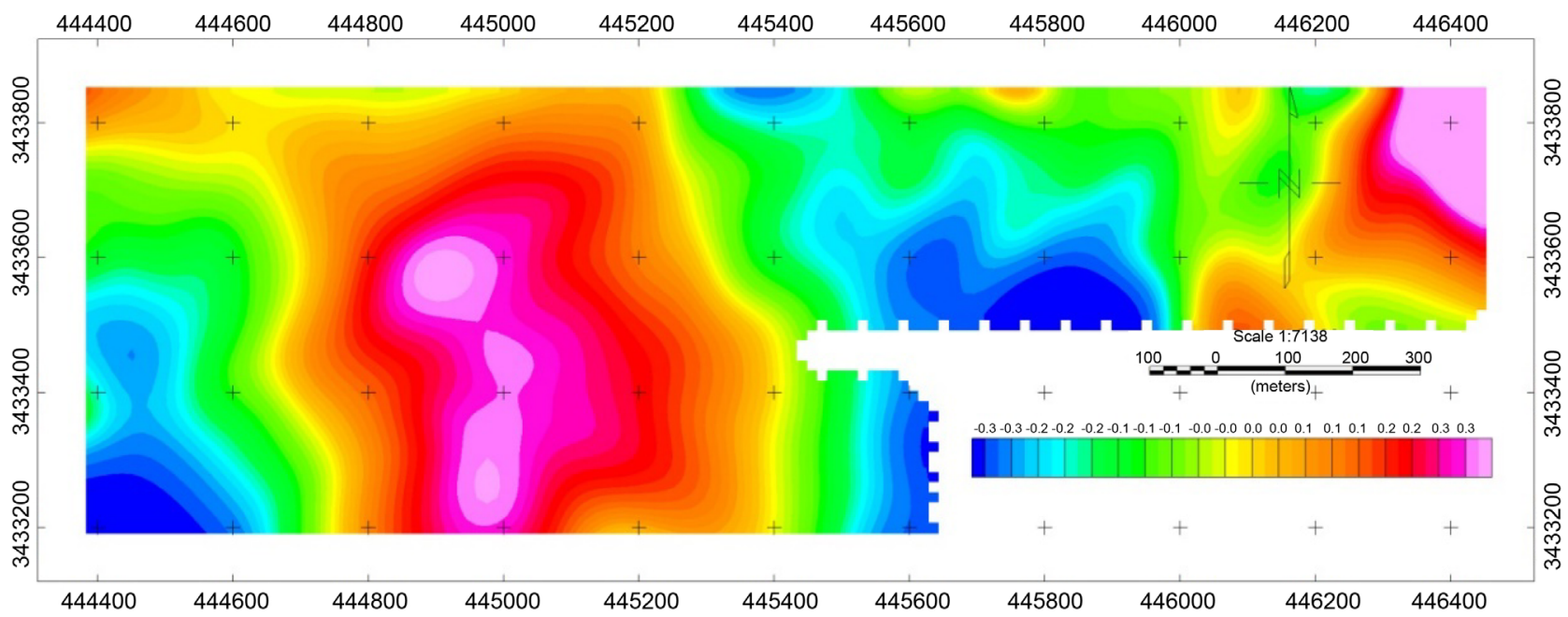

Figure 8. Map extends upwards with a height of 60 meters.

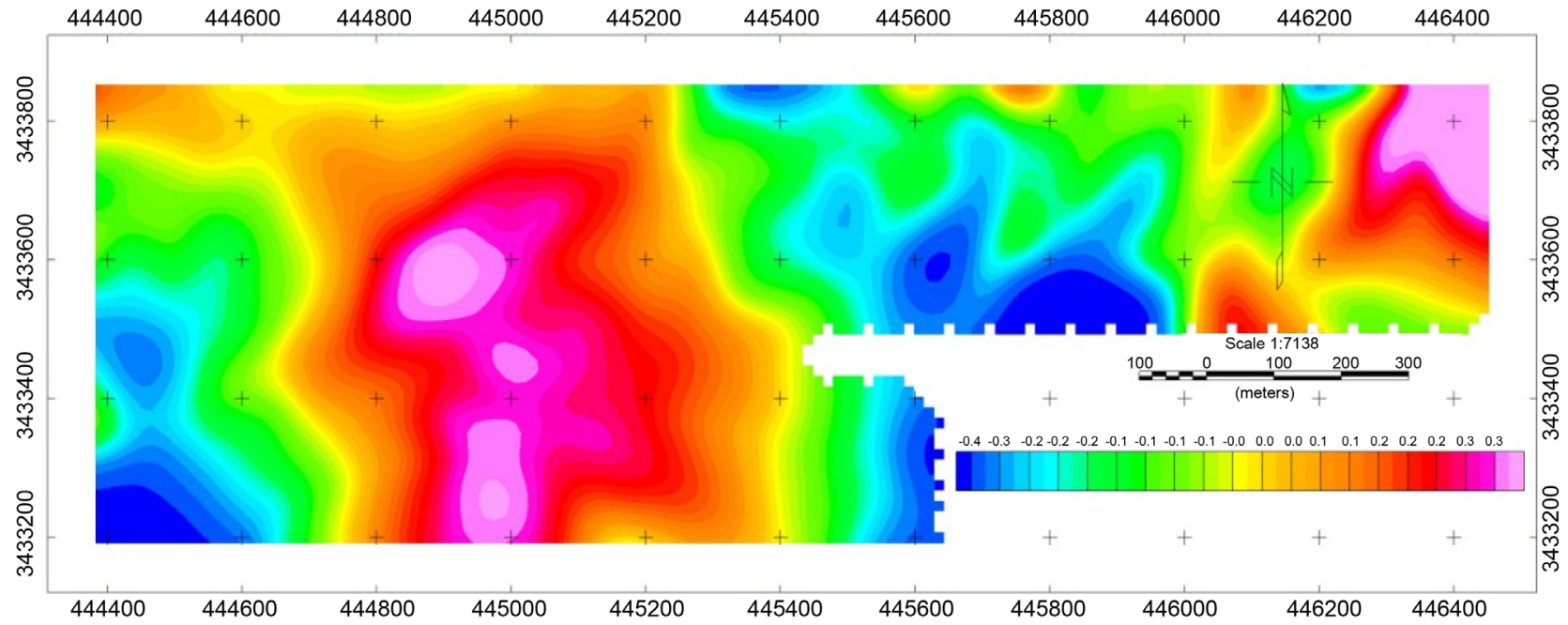

Figure 9. Map extends upwards with a height of 80 meters.

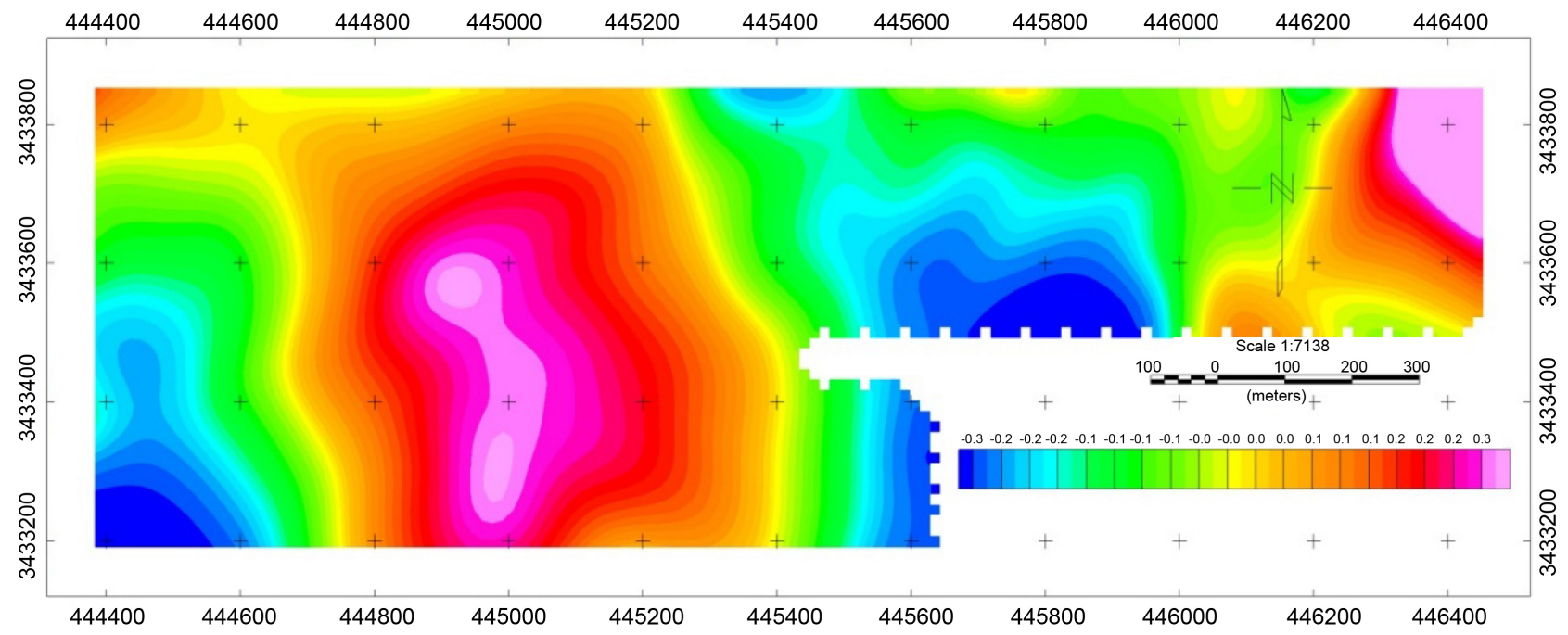

Figure 10. Map extends upwards with a height of 100 meters. 


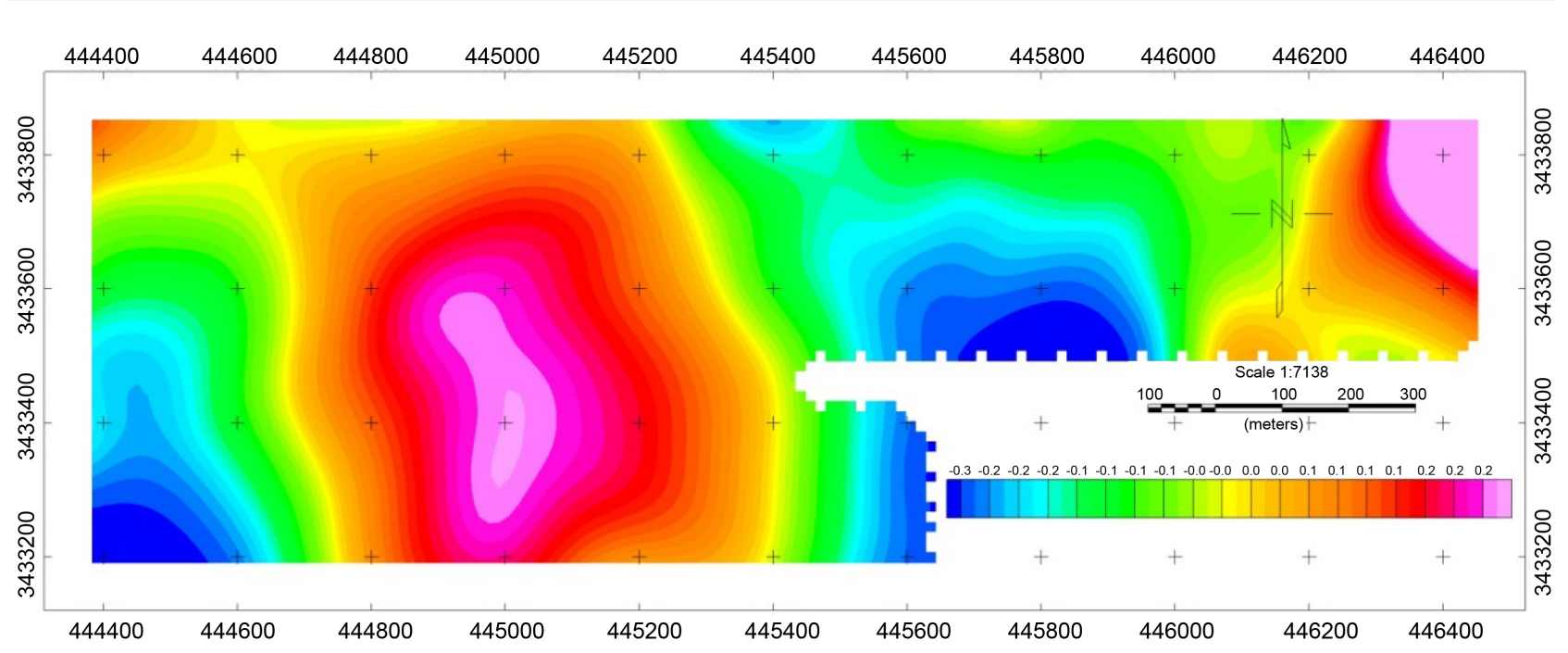

Figure 11. Map extends upwards with a height of 120 meters.

clearly. The second derivative is used to obtain surface effects very close to the ground, and the first derivative is used to obtain more profound surface effects. Different equations are used to calculate the derivative, which is generally presented in the following two ways [32] [35].

How to use Laplace equations:

$$
\frac{\mathrm{d}^{2} g}{\mathrm{dz}}=-\left(\frac{\mathrm{d}^{2} g}{\mathrm{~d} x^{2}}+\frac{\mathrm{d}^{2} g}{\mathrm{~d} y^{2}}\right)
$$

\subsubsection{Analytical Method}

By the analytical method, the exact value of the derivative can be calculated. To this end, geophysical researchers have proposed various relationships. These methods draw several concentric circles with different radii to the center of the point on which the calculation is performed. In this case, the value of the second derivative of the following relation is specified [36]:

$$
\frac{\mathrm{d}^{2} g}{\mathrm{~d} z^{2}}=\frac{c}{s^{2}}\left(w_{0} g_{0}+w_{1} \overline{g_{1}}+w_{2} \overline{g_{2}}+\cdots+w_{n} \overline{g_{n}}\right)
$$

where $\left(g_{0}\right)$ is the center of gravity of the circles, $\left(g_{1}, g_{2}, \ldots\right)$ are the mean values of gravity on successive circles, and $\left(w_{0}, w_{1}\right.$, etc.) are weight coefficients, so that we can write:

$$
\sum_{i=0}^{n} W_{i}=0
$$

$(C)$ is a fixed value, and $(s)$ is the length of the square grid. The radius of the circles varies according to the methods presented by different forms according to the sizes of the square grid. Metamorphic rocks of igneous origin with different self-susceptibility and the effect of the fault system have caused various interactions that have affected the complexity of the area. The vertical derivative filter is used to amplify surface anomalies (high frequency, low wavelength) and weaken deep anomalies, including the foundation stone of the area. Therefore, this filter 
is used to determine the anomaly's boundary and eliminate the effect of the surface trend. Before applying the vertical derivatives filter, the data should be examined for noise, and the data that cause the disturbance in this filter should be identified and removed or replaced from the data using statistical methods. After performing this step, the mentioned filter applies [37] [38].

The first and second-order vertical derivative maps were calculated and plotted as above and derived filters because they show outcrops, faults, and surface noise. In these maps, the noises are identified. An outcrop was not seen according to these maps and limited visits, and finally, no line is seen on the map. Figure 12 and Figure 13 show the study area's first and second derivative maps [39].

\section{Analytic signal map}

The analytical signal is a function of the quadratic power of the horizontal and vertical derivatives. Therefore, maps based on analytical signals show the turning

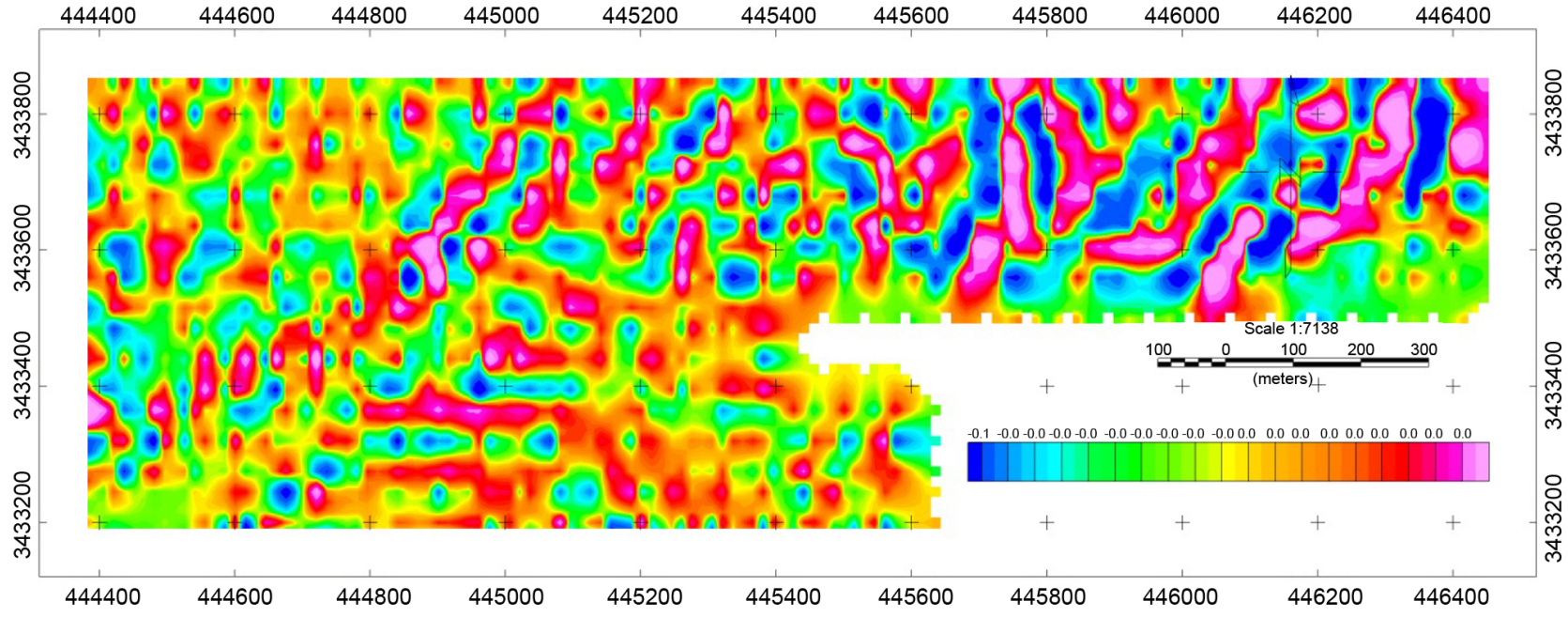

Figure 12. First-order vertical derivative map.

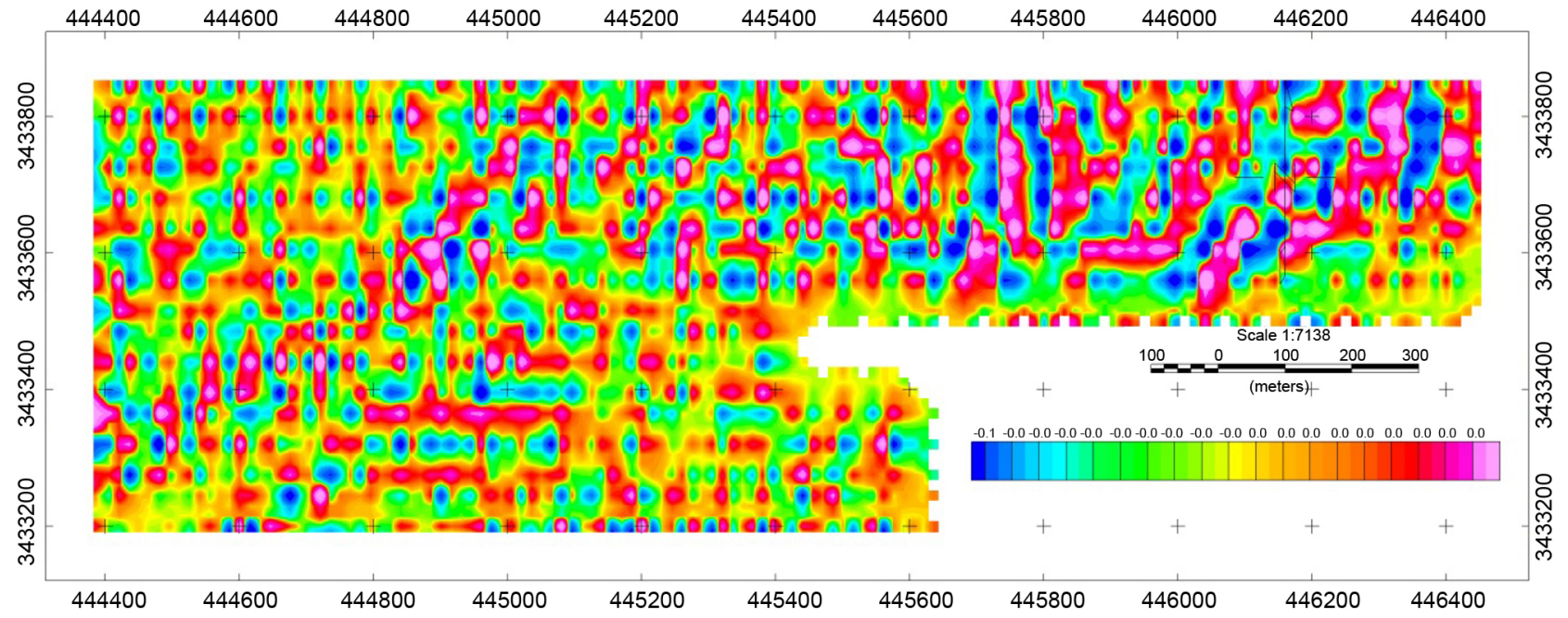

Figure 13. Second-order vertical derivative map. 
points of field change diagrams, and changes in potential field diagrams around the figures in this map reach their maximum and can be used to determine the boundaries of abnormal figures to some extent. Mathematical analysis, on the other hand, shows that higher values in analytical signal maps can be close to the center of anomalies, and in the case of severe anomalies due to small bodies, the maximum values can correspond to the center of the body [40] [41]. But in practice, this is not the case, and errors usually accompany these estimates.

Equation (11) shows the analytical signal equation:

$$
A S=\sqrt{\left(\frac{\partial g}{\partial x}\right)^{2}+\left(\frac{\partial g}{\partial y}\right)^{2}+\left(\frac{\partial g}{\partial z}\right)^{2}}
$$

Analytical signal mapping is widely used as an efficient and basic filter in transferring the anomaly location to its original location [42]. Analytical signal mapping in magnetic data is the only filter that can be applied to non-polarized data. Figure 14 shows the map of the analytical signal filter.

\subsection{Quantitative Interpretation}

The Euler Deconvolution method was first proposed by Hood (1965). Thompson (1982) then applied this method to artificial and accurate data [43]. Reed (1990) used this method as a grid analysis. Euler's homogeneous equation is in relation (12):

$$
\left(x-x_{0}\right) \frac{\partial \Delta G}{\partial y}+\left(y-y_{0}\right) \frac{\partial \Delta G}{\partial Z}-\left(z-z_{0}\right) \frac{\partial \Delta G}{\partial z}=-N \Delta G(x, y)
$$

$(N)$ is a structural index defined as the field deflection rate in terms of distance from the source and is selected based on previous information from the source geometry [14] [15]. (for gravimetric data $(N=0)$ for dykes, $(N=1)$ for horizontal cylinders and Vertical and $(N=2)$ for butter) [44].

$(G)$ The gravitational field measured in $(x, y, z)$ is generated by a point or linear source $\left(x_{0}, y_{0}, z_{0}\right)$. The Euler equation is solved by considering the four

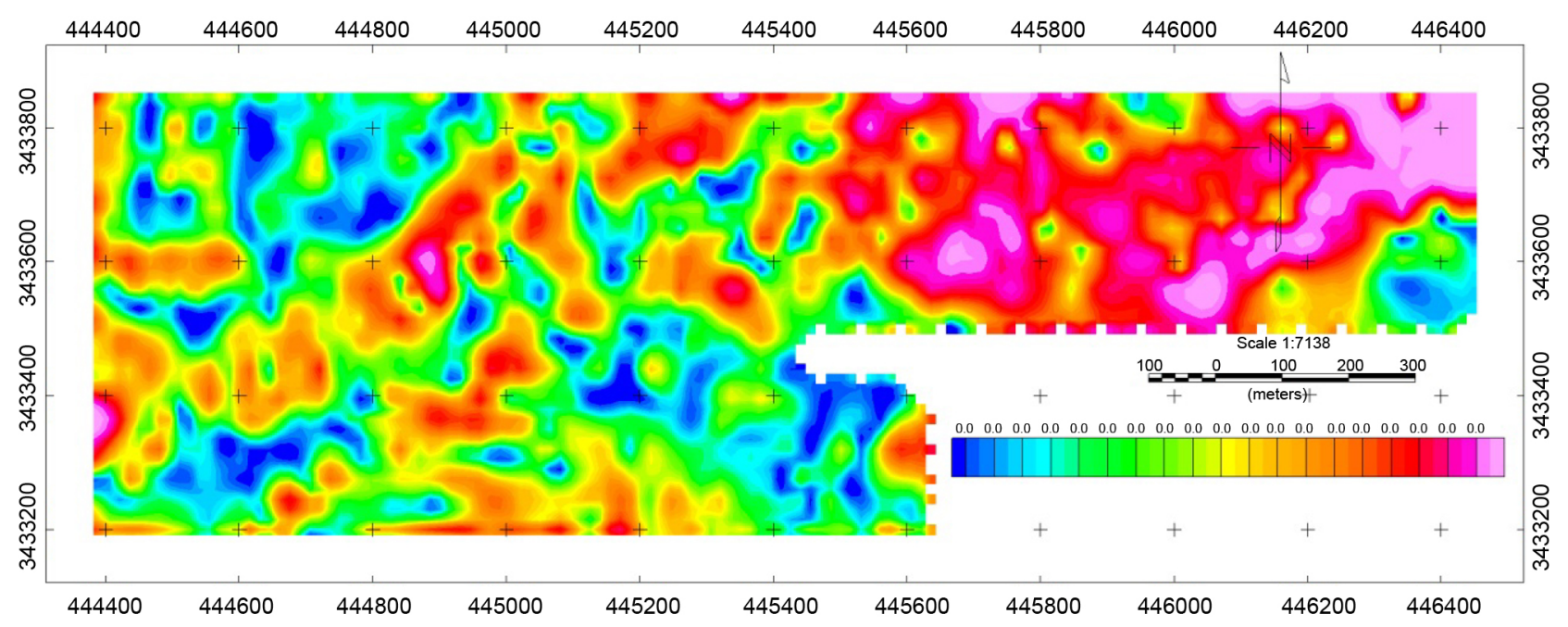

Figure 14. Analytical signal map. 


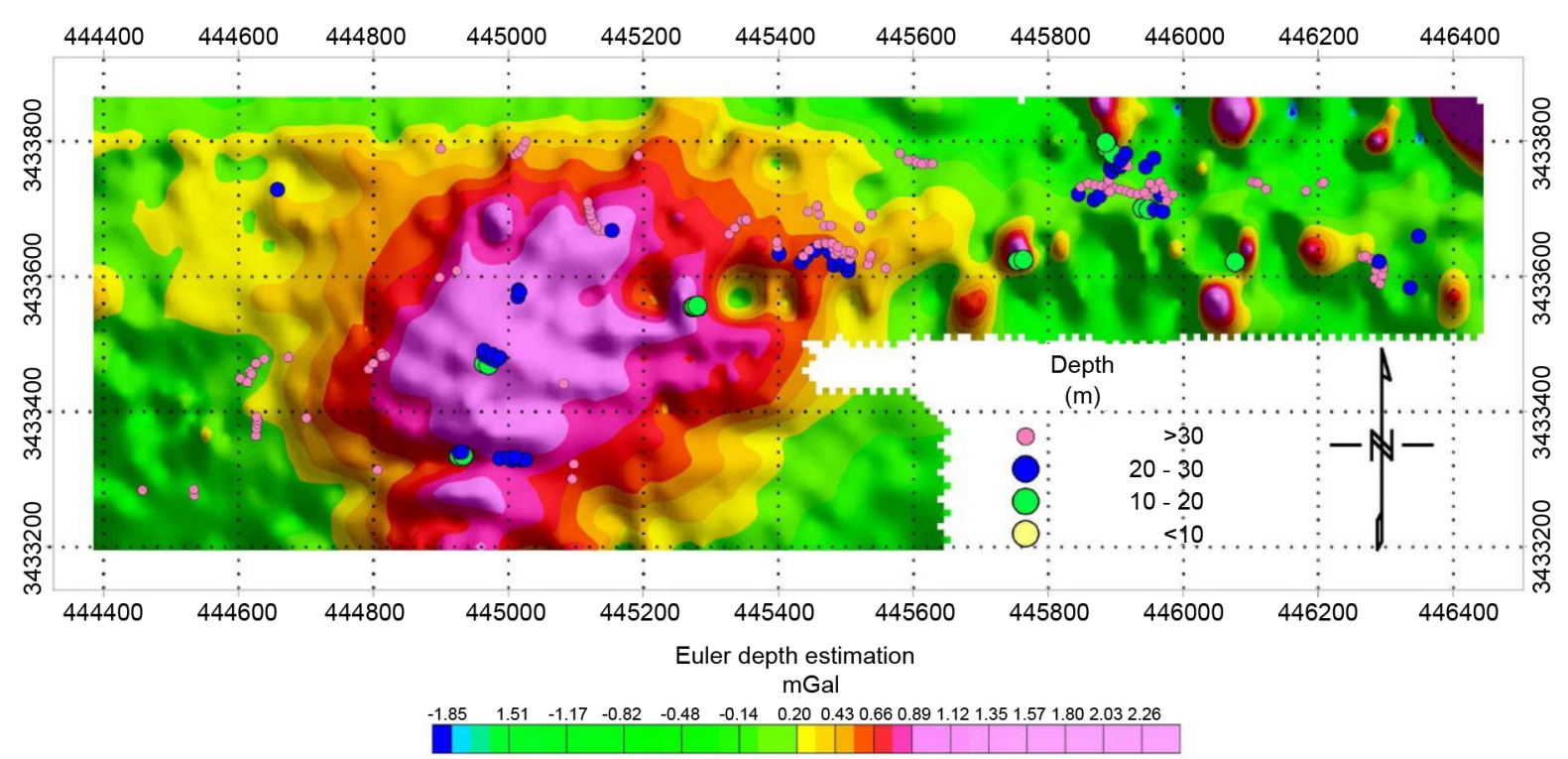

Figure 15. Depth estimation using Euler analysis.

measured points. Then, by moving the window from one point to another, the Euler equation is solved for the real anomaly of the whole field. One of the disadvantages of the Euler method is that it considers simple geometric models for the potential field source. Another disadvantage of the Euler method is that the structural index is determined based on previous information. However, Thompson (1982) and Reed (1990) determined the optimal structural indices for different structures. Nevertheless, the Euler method satisfactorily estimates the position and depth of potential sources (Figure 15).

\section{Conclusions}

- According to the Bouguer map, which shows the effect of masses causing anomalies at depth, changes in gravity acceleration have occurred in the region from bottom to top.

- The remaining anomaly map was drawn from the 1st- and 2nd-degree levels. Because the Level 2 map is a better confirmation of the anomaly, this map became the basis for interpretation.

- Upward expansion maps were drawn from 20 to $140 \mathrm{~m}$, and since the anomaly did not change much from 100 to $120 \mathrm{~m}$, the depth of the anomaly was considered to be about $100 \mathrm{~m}$.

- First- and second-order vertical derivative maps were drawn to identify outcrops, faults, and surface noise. In these maps, only the noises are clearly visible, while no outcrops or faults were seen.

- Finally, based on the analysis performed using the Euler method, the depth of the deposit was estimated at an average of 20 to 30 meters.

\section{Conflicts of Interest}

The authors declare no conflicts of interest regarding the publication of this paper. 


\section{References}

[1] Shirazi, A., Hezarkhani, A. and Shirazy, A. (2018) Remote Sensing Studies for Mapping of Iron Oxide Regions, South of Kerman, Iran. International Journal of Science and Engineering Applications, 7, 45-51. https://doi.org/10.7753/IJSEA0704.1002

[2] Shirazi, A., Shirazy, A., Saki, S. and Hezarkhani, A. (2018) Geostatistics Studies and Geochemical Modeling Based on Core Data, Sheytoor Iron Deposit, Iran. Journal of Geological Resource and Engineering, 6, 124-133.

[3] Alahgholi, S., Shirazy, A. and Shirazi, A. (2018) Geostatistical Studies and Anomalous Elements Detection, Bardaskan Area, Iran. Open Journal of Geology, 8, 697-710. https://doi.org/10.4236/ojg.2018.87041

[4] Shirazi, A., Shirazy, A. and Karami, J. (2018) Remote Sensing to Identify Copper Alterations and Promising Regions, Sarbishe, South Khorasan, Iran. International Journal of Geology and Earth Sciences, 4, 36-52.

[5] Shirazi, A., Shirazy, A., Saki, S. and Hezarkhani, A. (2018) Introducing a Software for Innovative Neuro-Fuzzy Clustering Method Named NFCMR. Global Journal of Computer Sciences. Theory and Research, 8, 62-69. https://doi.org/10.18844/gjcs.v8i2.3264

[6] Shirazi, A., Hezarkhani, A. and Shirazy, A. (2018) Exploration Geochemistry Data-Application for Cu Anomaly Separation Based On Classical and Modern Statistical Methods in South Khorasan, Iran. International Journal of Science and Engineering Applications, 7, 39-44. https://doi.org/10.7753/IJSEA0704.1001

[7] Shirazy, A., Shirazi, A., Ferdossi, M. and Ziaii, M. (2019) Geochemical and Geostatistical Studies for Estimating Gold Grade in Tarq Prospect Area by K-Means Clustering Method. Open Journal of Geology, 9, 306-326.

https://doi.org/10.4236/ojg.2019.96021

[8] Sabins, F.F. (1999) Remote Sensing for Mineral Exploration. Ore Geology Reviews, 14, 157-183. https://doi.org/10.1016/S0169-1368(99)00007-4

[9] Moon, C.J., Whateley, M.K. and Evans, A.M. (2006) Introduction to Mineral Exploration. Blackwell Publishing, Hoboken.

[10] Shirazy, A., Shirazi, A. and Nazerian, H. (2021) Application of Remote Sensing in Earth Sciences-A Review. International Journal of Science and Engineering Applications, 10, 45-51. https://doi.org/10.7753/IJSEA1005.1001

[11] Shirazy, A., Ziaii, M., Hezarkhani, A. and Timkin, T. (2020) Geostatistical and Remote Sensing Studies to Identify High Metallogenic Potential Regions in the Kivi Area of Iran. Minerals, 10, Article No. 869. https://doi.org/10.3390/min10100869

[12] Shirazy, A., Ziaii, M. and Hezarkhani, A. (2020) Geochemical Behavior Investigation Based on K-Means and Artificial Neural Network Prediction for Copper, in Kivi Region, Ardabil Province, Iran. Iranian Journal of Mining Engineering, 14, 96-112.

[13] Shirazy, A., Ziaii, M., Hezarkhani, A., Timkin, T.V. and Voroshilov, V.G. (2021) Geochemical Behavior Investigation Based on K-Means and Artificial Neural Network Prediction for Titanium and Zinc, Kivi Region, Iran. Известия Томского политехнического университета, 332, 113-125.

[14] Rodriguez-Galiano, V., Sanchez-Castillo, M., Chica-Olmo, M. and Chica-Rivas, M. (2015) Machine Learning Predictive Models for Mineral Prospectivity: An Evaluation of Neural Networks, Random Forest, Regression Trees and Support Vector Machines. Ore Geology Reviews, 71, 804-818.

https://doi.org/10.1016/j.oregeorev.2015.01.001

[15] Shirazi, A. and Hezarkhani, A. (2018) Predicting Gold Grade in Tarq 1: 100000 
Geochemical Map Using the Behavior of Gold, Arsenic and Antimony by K-Means Method. Journal of Mineral Resources Engineering, 2, 11-23.

[16] Shirazy, A., Shirazi, A., Heidarlaki, S. and Ziaii, M. (2018) Exploratory Remote Sensing Studies to Determine the Mineralization Zones around the Zarshuran Gold Mine. International Journal of Science and Engineering Applications, 7, 274-279. https://doi.org/10.7753/IJSEA0709.1004

[17] Khakmardan, S., Shirazi, A., Shirazy, A. and Hosseingholi, H. (2018) Copper Oxide Ore Leaching Ability and Cementation Behavior, Mesgaran Deposit in IRAN. Open Journal of Geology, 8, 841-858. https://doi.org/10.4236/ojg.2018.89049

[18] Kelly, E.G. and Spottiswood, D.J. (1982) Introduction to Mineral Processing. John Wiley \& Sons Inc., Hoboken.

[19] Khakmardan, S., Doodran, R., Shirazy, A., Shirazi, A. and Mozaffari, E. (2020) Evaluation of Chromite Recovery from Shaking Table Tailings by Magnetic Separation Method. Open Journal of Geology, 10, 1153-1163. https://doi.org/10.4236/ojg.2020.1012055

[20] Doodran, R.J., Khakmardan, S., Shirazi, A. and Shirazy, A. (2020) Minimalization of Ash from Iranian Gilsonite by Froth Flotation. Journal of Minerals and Materials Characterization and Engineering, 9, 1-13. https://doi.org/10.4236/jmmce.2021.91001

[21] Shirazi, A. and Shirazy, A. (2020) Introducing Geotourism Attractions in Toroud Village, Semnan Province, IRAN. International Journal of Science and Engineering Applications, 9, 79-86. https://doi.org/10.7753/IJSEA0906.1002

[22] Salem, A. and Ravat, D. (2003) A Combined Analytic Signal and Euler Method (AN-EUL) for Automatic Interpretation of Magnetic Data. Geophysics, 68, 1952-1961. https://doi.org/10.1190/1.1635049

[23] Hsu, S.-K., Sibuet, J.-C. and Shyu, C.-T. (1996) High-Resolution Detection of Geologic Boundaries from Potential-Field Anomalies: An Enhanced Analytic Signal Technique. Geophysics, 61, 373-386. https://doi.org/10.1190/1.1443966

[24] Vesali, Y. and Dariyush, E. (2016) Cadomian (Ediacaran-Cambrian) Arc Magmatism in the Jalal Abad Iron District, Nw Zarand, Central Iran. The 8th International Siberian Early Career GeoScientists Conference, Novosibirsk, 13-17 June 2016.

[25] Telford, W.M., Geldart, L.P. and Sheriff, R.E. (1990) Applied Geophysics. Cambridge University Press, Cambridge. https://doi.org/10.1017/CBO9781139167932

[26] Wang, J., Meng, X. and Li, F. (2017) New Improvements for Lineaments Study of Gravity Data with Improved Euler Inversion and Phase Congruency of the Field Data. Journal of Applied Geophysics, 136, 326-334.

https://doi.org/10.1016/j.jappgeo.2016.11.017

[27] Khayer, K., Shirazy, A., Shirazi, A., Ansari, A., Nazerian, H. and Hezarkhani, A. (2021) Determination of Archie's Tortuosity Factor from Stoneley Waves in Carbonate Reservoirs. International Journal of Science and Engineering Applications (IJSEA), 10, 107-110. https://doi.org/10.7753/IJSEA1008.1001

[28] Bott, M. (1960) The Use of Rapid Digital Computing Methods for Direct Gravity Interpretation of Sedimentary Basins. Geophysical Journal International, 3, 63-67. https://doi.org/10.1111/j.1365-246X.1960.tb00065.x

[29] Kazaryan, K., Burmin, V.Y. and Avetisyan, A. (2020) Comparison of Seismicity and Average Focal Mechanisms of Javakheti Highland Earthquakes with Regional Gravitational-Field Anomalies. Izvestiya, Atmospheric and Oceanic Physics, 56, 1423-1431. https://doi.org/10.1134/S0001433820110031 
[30] Thompson, D. (1982) EULDPH: A New Technique for Making Computer-Assisted Depth Estimates from Magnetic Data. Geophysics, 47, 31-37. https://doi.org/10.1190/1.1441278

[31] Huang, M.T., Liu, M., Deng, K.L., Ouyang, Y.Z., Lu, X.P., Zhai, G., et al. (2018) Analytical Solution of Downward Continuation for Airborne Gravimetry Based on Upward Continuation Method. Chinese Journal of Geophysics, 61, 4746-4757.

[32] Dogru, F., Pamukcu, O. and Ozsoz, I. (2017) Application of Tilt Angle Method to the Bouguer Gravity Data of Western Anatolia. Bulletin of the Mineral Research and Exploration, 155, 213-222. https://doi.org/10.19111/bulletinofmre.305177

[33] Reid, A.B., Allsop, J.M., Granser, H., Millett, A.J. and Somerton, I.W. (1990) Magnetic Interpretation in Three Dimensions Using Euler Deconvolution. Geophysics, 55, 80-91. https://doi.org/10.1190/1.1442774

[34] Veryaskin, A. and McRae, W. (2008) On Combined Gravity Gradient Components Modelling for Applied Geophysics. Journal of Geophysics and Engineering, 5, 348-356. https://doi.org/10.1088/1742-2132/5/3/010

[35] McElhinny, M. and McFadden, P.L. (1998) The Magnetic Field of the Earth: Paleomagnetism, the Core, and the Deep Mantle. Vol. 63, Academic Press, Cambridge.

[36] Wahyudi, E., Kynantoro, Y. and Alawiyah, S. (2017) Second Vertical Derivative Using 3-D Gravity Data for Fault Structure Interpretation. Journal of Physics. Conference Series, 877, Article ID: 012039. https://doi.org/10.1088/1742-6596/877/1/012039

[37] Hansen, R. and Suciu, L. (2002) Multiple-Source Euler Deconvolution. Geophysics, 67, 525-535. https://doi.org/10.1190/1.1468613

[38] FitzGerald, D., Reid, A. and McInerney, P. (2004) New Discrimination Techniques for Euler Deconvolution. Computer and Geoscience. 8th SAGA Biennial Technical Meeting and Exhibition, Pilanesberg, October 2003, cp-144-00024. https://doi.org/10.3997/2214-4609-pdb.144.24

[39] Blakely, R.J. (1996) Potential Theory in Gravity and Magnetic Applications. Cambridge University Press, Cambridge. https://doi.org/10.1017/CBO9780511549816

[40] Blakely, R.J. and Simpson, R.W. (1986) Approximating Edges of Source Bodies from Magnetic or Gravity Anomalies. Geophysics, 51, 1494-1498.

https://doi.org/10.1190/1.1442197

[41] Pham, L.T., Oksum, E., Do, T.D., Le-Huy, M., Vu, M.D. and Nguyen, V.D. (2019) LAS: A Combination of the Analytic Signal Amplitude and the Generalised Logistic Function as a Novel Edge Enhancement of Magnetic Data. Contributions to Geophysics \& Geodesy, 49, 425-440. https://doi.org/10.2478/congeo-2019-0022

[42] Ekinci, Y.L., Özyalın, Ş., Sındırgı, P., Balkaya, Ç. and Göktürkler, G. (2017) Amplitude Inversion of the 2D Analytic Signal of Magnetic Anomalies through the Differential Evolution Algorithm. Journal of Geophysics and Engineering, 14, 1492-1508. https://doi.org/10.1088/1742-2140/aa7ffc

[43] Pham, L.T., Oksum, E. and Do, T.D. (2019) Edge Enhancement of Potential Field Data Using the Logistic Function and the Total Horizontal Gradient. Acta Geodaetica et Geophysica, 54, 143-155. https://doi.org/10.1007/s40328-019-00248-6

[44] Pocasangre, C., Fujimitsu, Y. and Nishijima, J. (2020) Interpretation of Gravity Data to Delineate the Geothermal Reservoir Extent and Assess the Geothermal Resource from Low-Temperature Fluids in the Municipality of Isa, Southern Kyushu, Japan. Geothermics, 83, Article ID: 101735.

https://doi.org/10.1016/j.geothermics.2019.101735 